\title{
MRI of myositis and other urgent muscle-related disorders
}

\author{
Paul L. Wasserman ${ }^{1}$ (D) $\cdot$ Ashley Way ${ }^{1} \cdot$ Saif Baig ${ }^{1} \cdot$ Dheeraj Reddy Gopireddy $^{1}$
}

Received: 1 September 2020 / Accepted: 22 October 2020 / Published online: 9 November 2020

(C) American Society of Emergency Radiology 2020

\begin{abstract}
Myositis has many etiologies, and it can be encountered in the acute or chronic setting. Our goal is to increase the radiologist's knowledge of myositis and other urgent muscle disorders encountered in the emergent or urgent setting. We review the clinical presentation, the MRI appearance, and the complications that can be associated with these entities. Since myositis can affect multiple muscle compartments, we review how to differentiate the compartments of the appendicular skeletal in order to generate reports that relay important anatomic information to the treating physician. Given the poor sensitivity and positive predictive value of the clinical signs and symptoms used to diagnosing acute compartment syndrome, we discuss the potential use of MRI in cases of suspected but clinically equivocal compartment syndrome in the future.
\end{abstract}

Keywords Myositis $\cdot$ Rhabdomyolysis $\cdot$ Compartment syndrome $\cdot$ Anatomy $\cdot$ MRI

\section{Introduction}

Recent data indicates that musculoskeletal complaints comprise $15 \%$ of all emergency department encounters [1]. A small, but potentially urgent percentage of these cases may involve myositis. Myositis is a broad term used to describe inflammation of muscle tissue but has many etiologies. In its chronic form, myositis is associated with connective tissue or autoimmune inflammatory cascades, primarily managed by rheumatologists. Our focus is on the more acute manifestations of myositis that might present to an emergency department, urgent care center, or as a complication of a newly admitted inpatient. Specifically, we look at the spectrum of MRI findings and the role MRI has in the diagnosis, management, and treatment of myositis and other urgent musclerelated disorders. With the increased utilization of MRI, on-

Paul L. Wasserman

Paul.wasserman@jax.ufl.edu

Ashley Way

Ashley.Way@jax.ufl.edu

Saif Baig

saif.baigmd@gmail.com

Dheeraj Reddy Gopireddy

DheerajReddy.Gopireddy@jax.ufl.edu

1 University of Florida-College of Medicine Jacksonville, 655 West 8th Street C90, Jacksonville, FL 32209, USA call radiologists may need to interpret these cases without the benefit of fellowship-trained musculoskeletal imaging expertise.

\section{MR imaging of myositis}

Currently, MR myositis protocols are characteristically brief, using a fluid-sensitive sequence such as short TI inversion recovery (STIR) or proton density with fat saturation in the axial and coronal planes as well as an axial T1 sequence. The brevity of the protocol reflects the inherent sensitivity of MR in the detection of abnormal muscle signal over specificity. The use of composed MR post-processing technique helps to seamlessly link upper and lower components of the arms or legs. Occasionally, paraspinal muscles and shoulders are imaged when clinically indicated.

In general, MRI has been criticized for long scan times, difficulty of access, and lack of specificity. However, with the ever-increasing accessibility, more efficient image acquisition, and the clinical use of techniques formerly reserved for research or less acute entities, emergent MRI could be useful in the diagnosis of myositis and even cases complicated by acute compartment syndrome (ACS). The inconsistent performance of intracompartmental pressure measurements has spawned research into the biochemical markers of impending irreversible muscle ischemia. Pyruvate and phosphocreatine levels have been shown to decrease in the setting of muscle 
glycolysis (anaerobic respiration). Conversely, lactate concentration has been shown to increase, leading to decreased tissue $\mathrm{pH}$ [2]. Efforts are in progress to measure muscle compartment $\mathrm{pH}$ by using an indwelling catheter or needle; however, P31 magnetic resonance spectroscopy (MRS) has proven to accurately measure intracellular $\mathrm{pH}$ in a noninvasive manner $[3,4]$. MRS uses the relative chemical shift of inorganic phosphate $(\mathrm{Pi})$ and phosphocreatine $(\mathrm{PCr})$ to calculate $\mathrm{pH}$ using the Henderson-Hasselbalch equation. Sedivy et al. reported a scan time of 4 min using a 3T system [4]. Another emerging technology is MR elastography (MRE). MRE "measures tissue stiffness by encoding displacements due to the propagation of externally induced acoustic waves into the MR phase signal" [5]. The inherent tissue stiffness affects the speed of the wave propagation, with stiffer tissue inducing faster wave speed. It remains to be seen whether the muscle compartment tension associated with myositis and ACS coincides with measurable tissue stiffness afforded by MRE. Ultimately, one could conceive of an abbreviated ACS protocol that uses isotopic 3D volume acquisition combined with P31-MRS and MRE to yield anatomic and biochemical information. Such an endeavor would require specialized software, a streamlined patient selection protocol, and close coordination between the radiologist and technologist; however, with the proper equipment, the idea is imaginable. Incorporating an artificial intelligence automation tool could assist with data processing in order to optimize the turn-around time for these cases. Potentially, cases of suspected but clinically equivocal ACS may benefit from this type of MRI imaging in the future.

\section{Anatomy}

A thorough understanding of compartmental anatomy is necessary to adequately describe MR imaging findings of myositis and its complications. Accurate localization of the abnormalities can help clinicians understand the extent of disease and whether the process is affecting adjacent structures such as bone, joint space, bursa, tendons, and neurovascular bundles. The compartments are space-limited areas, confined by the deep and intermuscular fascia.

\section{Upper extremity}

The upper extremity anatomy can be divided into the arm and the forearm (Table 1). The muscle compartments of the arm are separated into anterior and posterior compartments by the medial and lateral intermuscular septa, which are fascia thickenings that extend from the humerus to the deep fascia (Fig. 1a). The long and short heads of the biceps make up the superficial muscles of the anterior compartment, while the coracobrachialis and brachialis make up the deeper muscles of the compartment. The three heads of the triceps muscle (long, lateral, and medial) occupy the posterior compartment in toto. The deltoid muscle is not included in the arm compartment schema [6].

The description of the forearm is more variable with two, three, and four compartments cited in the literature [7]. In the four compartment classification, there are dorsal, mobile wad of Henry, volar superficial, and volar deep compartments. Anatomically, the forearm compartments are often
Table 1 Anatomy (upper and lower extremities)

\begin{tabular}{|c|c|c|c|}
\hline Extremity & Division & Compartment & Muscles \\
\hline \multirow[t]{4}{*}{ Upper } & \multirow[t]{2}{*}{ Arm } & Anterior & Long and short heads of the biceps, coracobrachialis, brachialis \\
\hline & & Posterior & Long, lateral, medial heads of the triceps \\
\hline & \multirow[t]{2}{*}{ Forearm } & Volar & $\begin{array}{l}\text { Pronator teres, palmaris longus, flexor digitorum superficialis, flexor } \\
\text { carpi ulnaris, flexor pollicis longus, flexor digitorum profundus }\end{array}$ \\
\hline & & Dorsal & $\begin{array}{l}\text { Brachioradialis, supinator, extensor carpi radialis longus, extensor } \\
\text { carpi radialis brevis, extensor digitorum, extensor digiti minimi, } \\
\text { extensor carpi ulnaris, extensor pollicis brevis, extensor pollicis } \\
\text { longus }\end{array}$ \\
\hline \multirow[t]{7}{*}{ Lower } & \multirow[t]{3}{*}{ Thigh } & Anterior & $\begin{array}{l}\text { Sartorius, rectus femoris, vastus medialis, vastus intermedius, vastus } \\
\text { lateralis }\end{array}$ \\
\hline & & Medial & Adductor longus, gracilis, adductor brevis, adductor magnus \\
\hline & & Posterior & $\begin{array}{l}\text { Biceps femoris long and short heads, semitendinosus, } \\
\text { semimembranosus }\end{array}$ \\
\hline & \multirow{4}{*}{$\begin{array}{c}\text { Lower } \\
\text { leg }\end{array}$} & Anterior & Tibialis anterior, extensor hallucis longus, extensor digitorum longus \\
\hline & & Lateral & Peroneus longus, peroneus brevis \\
\hline & & $\begin{array}{l}\text { Deep } \\
\text { posterior }\end{array}$ & Tibialis posterior, flexor hallucis longus, flexor digitorum longus \\
\hline & & $\begin{array}{l}\text { Superficial } \\
\text { posterior }\end{array}$ & Medial gastrocnemius, lateral gastrocnemius, soleus \\
\hline
\end{tabular}




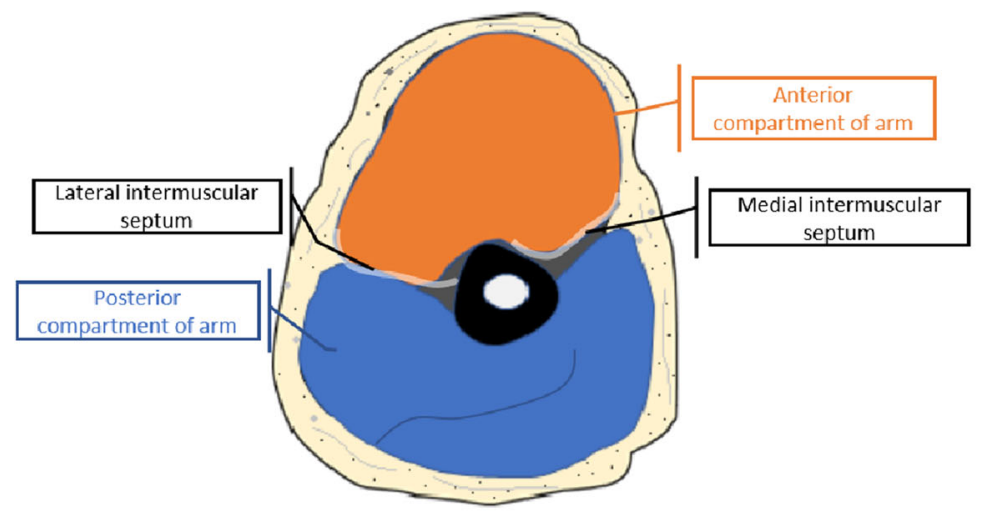

a.

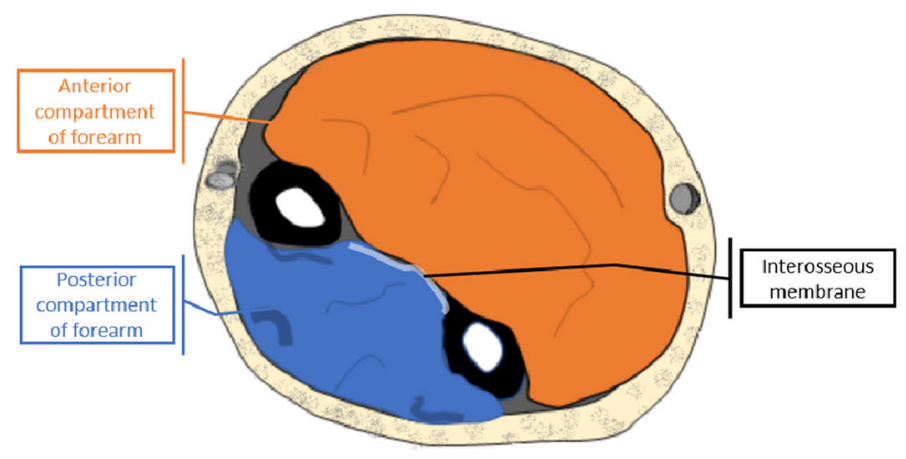

b.

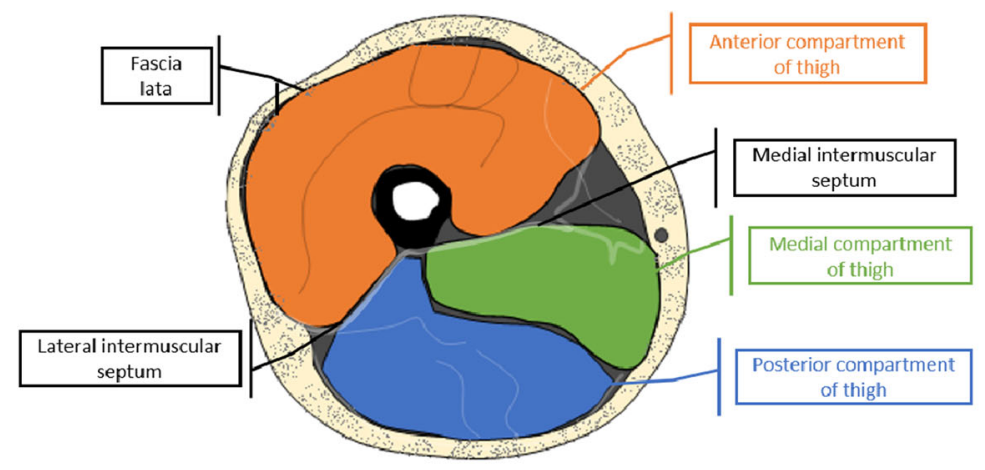

c.

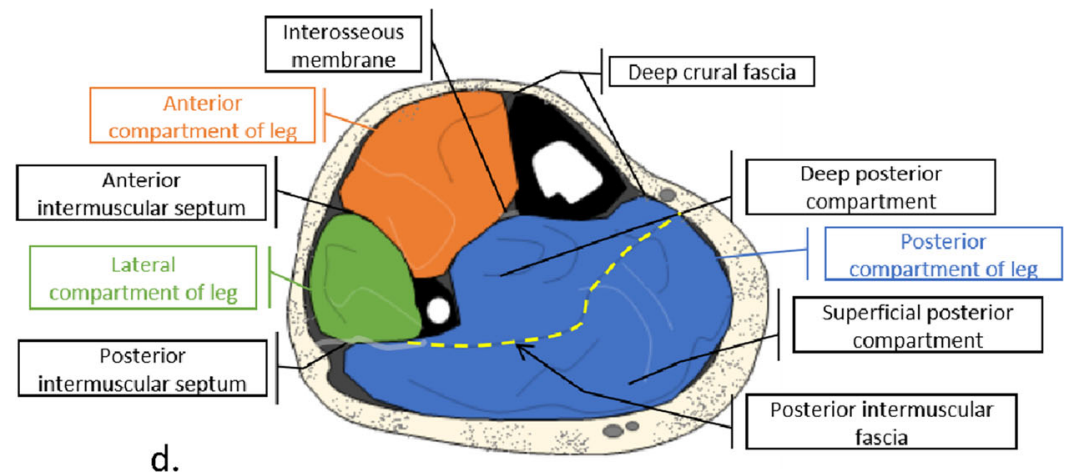

Fig. 1 Images of anatomic compartments 
incompletely separated, and for the purpose of this discussion, can be thought of as either dorsal or volar (Table 1). These two compartments are separated by the radius, ulna, and the intraosseous membrane which spans these bones (Fig. 1b). Due to the porous nature of the forearm compartments, often a single fasciotomy will suffice, releasing tension in the remaining compartments [6].

\section{Lower extremity}

The lower extremity anatomy can be divided into the thigh and the lower leg (Table 1). The thigh has three anatomic compartments: anterior, medial, and posterior. The fascia lata defines the circumferential superficial border investing all three compartments. The anterior compartment is separated from the medial and posterior compartments by fascial thickenings called the medial and lateral intermuscular septa that extend from either side of the femur to the fascia lata [8]. The medial compartment is separated from the posterior compartment by a thin fascial plane called the posterior intermuscular septum (Fig. 1c). The gluteus maximus is not included in the thigh compartment schema [9].

The lower leg is comprised of four anatomic compartments: anterior, lateral, superficial posterior, and deep posterior (Table 1). The deep crural fascia defines the circumferential superficial border investing all four compartments, and it fuses with the anterior periosteum of the tibia. The lateral compartment is separated from the anterior and posterior compartments by the anterior and posterior intermuscular septa, respectively. The posterior compartment is divided by the posterior intermuscular fascia into deep and superficial compartments (Fig. 1d). The interosseous membrane bridges the tibia and fibula, separating the anterior and deep posterior compartments [8].

\section{Etiologies and entities}

\section{Infectious myositis}

Infectious myositis is a type of urgent myositis that can present to the emergency department and can be bacterial or viral. Bacterial pyomyositis typically emanates from hematogenous bacteremia, with patients exhibiting three stages (Table 2). Patients in stage 1 present with localized pain, low-grade pyrexia, and malaise, but purulence is not present. Stage 2 of the disease presents with overt signs of local and systemic infection and usually follows stage 1 by 10 to 21 days. Severe muscle pain, swelling, and skin erythema can be present at this stage. Inflammatory markers and white blood cells become elevated. Frank pus and intramuscular abscesses can be present in stage 2. Stage 3 patients exhibit signs and symptoms of sepsis and complications that may involve other organ systems, including renal failure. Staphylococcus aureus is the most commonly isolated organism in pyomyositis $[10,11]$.

MRI is the imaging modality of choice for suspected pyomyositis. MRI has inherent qualities that allow us to differentiate tissue properties with marked sensitivity. Combined with intravenous contrast, MRI is excellent at distinguishing the rim-enhancing fluid collections that mark the transition from a phlegmonous stage 1 to a purulent stage 2. In stage 1 pyomyositis, one can expect muscle enlargement with loss of definition and heterogenous increased T2-weighted signal abnormalities (Fig. 2). T1-weighted sequences are usually isointense to slightly hyperintense depending on the proteinaceous nature of the fluid. In the late stage 2, T2-weighted images reveal hyperintensity with corresponding hypointense T1 signal. At this stage, post-contrast T1-weighted images with fat saturation may depict rounded or irregularly shaped rim-enhancing fluid collections that are typical of abscesses. MRI helps to identify percutaneously drainable fluid collections and surgical planning if necessary. Up to $40 \%$ of pyomyositis cases involve multiple muscle groups $[10,11]$.

Necrotizing fasciitis is an infection that can occur concomitantly with pyomyositis or as a distinct entity. The imaging hallmarks of this type of infection are the result of fascial inflammation and necrosis that leads to fascial thickening, interfascial fluid, and perifascial hyperemic changes, often in multiple compartments [12]. Thickening of the deep and intermuscular fascia greater than $3 \mathrm{~mm}$ is associated with $86 \%$ of necrotizing fasciitis when compared to nonnecrotizing fasciitis [12]. The accumulation of fluid along the fascial planes results in hyperintense $\mathrm{T} 2$ signal and hypointense T1 signal. Enhancement is variable, likely due to the disruption of capillary networks traversing the deep fascial planes [12]. Crepitus is the physical sign representing subcutaneous emphysema tracking along fascial planes. This gas is readily identified using conventional radiographs and CT; however, only a minority of cases involves gas-forming organisms. Gradient-echo sequences can help to identity gas on MRI scans. While MRI can yield exquisite tissue contrast and could be useful to map the extent of the disease to aid surgical planning, treatment should not be delayed in lieu of imaging in severely toxic patients [13].

Viral infections are commonly associated with myositis which can range from mild myalgias to rhabdomyolysis, leading to renal failure and cardiac arrhythmias [14]. Multiple viruses have been implicated in myositis and myositisinduced rhabdomyolysis including influenza A/B; parainfluenza; coxsackie; hepatitis A, B, C, and E; and HIV [14-16]. Toscana, Dengue, and West Nile viruses have also been documented causes of viral-related myositis [17]. Recently, Beydon et al. presented an MRI documented case of SARS-CoV-2-related myositis of the external obturator and vastus lateralis muscles [18]. The mechanism of viral-related 
Table 2 Etiologies, entities, and special features

\begin{tabular}{|c|c|c|c|c|c|}
\hline Etiology/entity & MRI T1-weighted & $\begin{array}{l}\text { MRI T2- } \\
\text { weighted }\end{array}$ & Special features & Clinical presentation & Other \\
\hline $\begin{array}{l}\text { Bacterial } \\
\text { pyomyositis }\end{array}$ & $\begin{array}{l}\text { Isointense to slightly } \\
\text { hyperintensity } \\
\text { depending on } \\
\text { proteinaceous fluid } \\
\text { content }\end{array}$ & $\begin{array}{l}\text { Heterogeneously } \\
\text { hyperintense } \\
\text { signal }\end{array}$ & $\begin{array}{l}\text { Irregular, thickened, } \\
\text { rim-enhancing ab- } \\
\text { scesses accentuated } \\
\text { with T1 fat sat + } \\
\text { contrast }\end{array}$ & $\begin{array}{l}\text { Stage } 1 \text {-localize pain, low-grade } \\
\text { fever, malaise } \\
\text { Stage } 2 \text { - severe, pain, swelling, } \\
\text { skin erythema, purulence } \\
\text { Stage } 3 \text { - sepsis and multi-organ } \\
\text { system damage }\end{array}$ & $\begin{array}{l}\text { S. aureus is most common in } \\
\text { pyomyositis }\end{array}$ \\
\hline $\begin{array}{l}\text { Necrotizing } \\
\text { fasciitis }\end{array}$ & $\begin{array}{l}\text { Hypointense to } \\
\text { isointense signal }\end{array}$ & $\begin{array}{l}\text { Hyperintense } \\
\text { signal }\end{array}$ & $\begin{array}{l}\text { Fascial thickening } \\
>3 \mathrm{~mm} \\
\text { Interfascial fluid } \\
\text { Perifascial edema in } \\
\text { multiple } \\
\text { compartments } \\
\text { Variable enhancement }\end{array}$ & $\begin{array}{l}\text { Rapidly progressing infection } \\
\text { Crepitus/subcutaneous gas in } \\
\text { minority of cases }\end{array}$ & $\begin{array}{l}\text { Can occur concomitantly with } \\
\text { pyomyositis }\end{array}$ \\
\hline Viral infections & $\begin{array}{l}\text { Hypointense to } \\
\text { isointense signal }\end{array}$ & $\begin{array}{l}\text { Hyperintense } \\
\text { signal }\end{array}$ & $\begin{array}{l}\text { Patchy or streaky } \\
\text { infiltration of muscle } \\
\text { with heterogenous or } \\
\text { diffuse enhancement }\end{array}$ & $\begin{array}{l}\text { Mild to severe myalgias } \\
\text { Can progress to rhabdomyolysis }\end{array}$ & $\begin{array}{c}\text { Most commonly: influenza A/B, } \\
\text { parainfluenza, coxsackie, } \\
\text { hepatitis A, B, C, E, and HIV }\end{array}$ \\
\hline Rhabdomyolysis & $\begin{array}{l}\text { Type } \\
\text { 1-homogeneously } \\
\text { isointense to faintly } \\
\text { hyperintense } \\
\text { Type 2-homogeneous } \\
\text { or heterogeneous } \\
\text { isointense to faintly } \\
\text { hyperintense }\end{array}$ & Type & $\begin{array}{l}\text { 1-homogenously } \\
\text { high signal } \\
\text { Type 2-heterogenous } \\
\text { hyperintensity }\end{array}$ & $\begin{array}{l}\text { Type 1-homogenous enhance- } \\
\text { ment } \\
\text { Type 2-rim enhancing collections, } \\
\text { myonecrosis "stipple sign" }\end{array}$ & $\begin{array}{l}\text { Muscle pain, weakness, } \\
\text { dark-colored urine } \\
\text { Markedly elevated CK } \\
\text { Can lead to renal failure and fatal } \\
\text { cardiac arrhythmias }\end{array}$ \\
\hline $\begin{array}{l}\text { Multiple causes: } \\
\text { overexertion, } \\
\text { exercise, } \\
\text { blunt trauma, } \\
\text { vascular } \\
\text { occlusion, } \\
\text { carbon } \\
\text { monoxide } \\
\text { poisoning, or } \\
\text { medication } \\
\text { induced }\end{array}$ & & & & & \\
\hline IMNM & $\begin{array}{l}\text { Isointense with } \\
\text { hyperintense }\end{array}$ & Hyperintense & $\begin{array}{l}\text { Edema, atrophy, fatty } \\
\text { replacement }\end{array}$ & Muscle weakness, very high CK & $\begin{array}{l}\text { Autoantibodies of anti-HMGCR or } \\
\text { anti-SRP, associated with statin } \\
\text { use }\end{array}$ \\
\hline $\begin{array}{l}\text { Diabetic } \\
\text { myonecrosis } \\
\text { (DMN) }\end{array}$ & $\begin{array}{l}\text { Isointense to faintly } \\
\text { hyperintense }\end{array}$ & Hyperintense & $\begin{array}{l}\text { Subfascial and } \\
\text { subcutaneous edema } \\
\text { Can have small } \\
\text { rim-enhancing col- } \\
\text { lections with } \\
\text { hypointense foci } \\
\text { with T1 fat sat + C }\end{array}$ & $\begin{array}{l}\text { Acute onset of pain, with or } \\
\text { without mass, decreased range } \\
\text { of motion, low-grade fever, } \\
\text { mildly elevated CK } \\
\text { Predominately effects lower } \\
\text { extremities and can be } \\
\text { multifocal }\end{array}$ & $\begin{array}{l}\text { Long-standing, uncontrolled } \\
\text { complicated diabetes often with } \\
\text { nephropathy, neuropathy, and } \\
\text { retinopathy }\end{array}$ \\
\hline $\begin{array}{l}\text { Acute } \\
\text { compartment } \\
\text { syndrome } \\
\text { (ACS) }\end{array}$ & $\begin{array}{l}\text { Isointense to faintly } \\
\text { hyperintense with } \\
\text { swelling and loss of } \\
\text { muscle architecture }\end{array}$ & Hyperintense & $\begin{array}{l}\text { Variable enhancement } \\
\text { of the affected } \\
\text { muscle and } \\
\text { subfascial regions }\end{array}$ & $\begin{array}{l}\text { Signs and symptoms of six P's } \\
\text { Sustained ICP of }>30 \mathrm{mmHg} \text { or } \\
\text { perfusion pressure (diastolic } \\
\text { BP-ICP) less than } 30 \mathrm{mmHg}\end{array}$ & $\begin{array}{l}\text { Blunt, crush, penetrating trauma } \\
\text { most commonly of the anterior } \\
\text { compartment of the tibia }\end{array}$ \\
\hline $\begin{array}{l}\text { Overdose } \\
\text { compartment } \\
\text { syndrome } \\
\text { (ODCS) }\end{array}$ & $\begin{array}{l}\text { Isointense to faintly } \\
\text { hyperintense with } \\
\text { swelling and loss of } \\
\text { muscle architecture }\end{array}$ & $\begin{array}{l}\text { Diffuse or patchy } \\
\text { hyperintense }\end{array}$ & $\begin{array}{l}\text { Variable enhancement } \\
\text { depending on degree } \\
\text { of tissue } \\
\text { devitalization } \\
\text { Late findings of fibrosis } \\
\text { and fatty infiltration }\end{array}$ & $\begin{array}{l}\text { Patient "found down" with } \\
\text { overlapping clinical and } \\
\text { imaging findings of } \\
\text { rhabdomyolysis and/or com- } \\
\text { partment syndrome }\end{array}$ & $\begin{array}{l}\text { More likely to present with gluteal } \\
\text { involvement than ACS }\end{array}$ \\
\hline
\end{tabular}

Abbreviations:

T1 fat sat + C (T1 fat saturation with contrast)

S. aureus (Staphylococcus aureus)

CK (creatine kinase)

ICP (intracompartment pressure)

IMNM (immune-mediated necrotizing myopathy)

Anti-HMGCR (anti-3-hydroxy-3-methylglutaryl-coenzyme A reductase)

Anti-SRP (anti-signal recognition particle) 


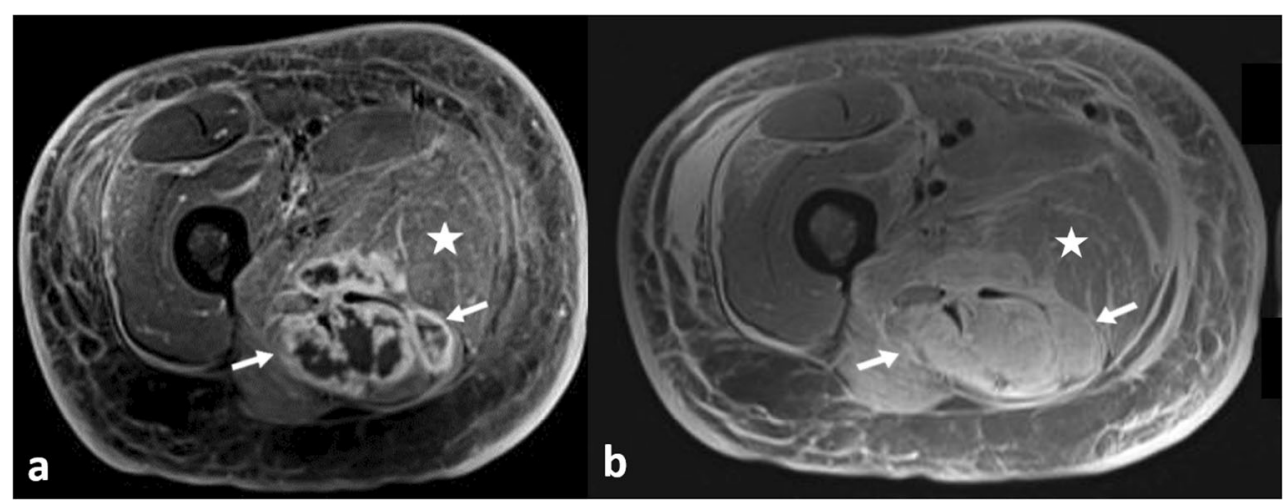

Fig. 2 a Stage 2, pyomyositis in a 36-year-old immunosuppressed patient with an irregularly shaped, multiloculated, peripherally enhancing abscess within the posterior compartment of the proximal thigh on this T1 fat-saturated post-contrast image (arrows). Note the enhancement of the surrounding musculature consistent with infectious myositis (star). Axial

myositis is unclear; however, direct viral invasion, viralmediated myotoxic cytokines, and viral-induced autoimmune reaction have all been posited [14] (Fig. 3).

The MRI appearance of viral-related myositis varies by extent and distribution; however, streaky or patchy infiltration of muscle by abnormally high T2-weighted signal is a common theme. Heterogeneous or diffuse enhancement of muscle lesions is often seen $[17,18]$.

\section{Rhabdomyolysis}

Rhabdomyolysis can occur as a complication of myositis resulting from a myriad of viral, exertional, toxic, and crush etiologies. Sarcolemma membrane disruption causes myoglobin, potassium, phosphate, creatine kinase (CK), and urate to leak into the systemic circulation [19]. Myoglobin exhibits direct toxic effects that are detrimental to renal blood flow, leading to renal ischemia, and the production of myoglobin casts that cause proximal tubular necrosis [14]. Between 4 and proton density with fat saturation at the same level $\mathbf{b}$ reveals an abnormal area of increased signal intensity that corresponds to the abscess; however, is less well defined (arrows). Increased signal is also noted in the adjacent muscle (star)

$40 \%$ of rhabdomyolysis patients experience acute renal failure [14]. Severe cases exhibit the clinical triad of muscle pain, weakness, and dark-colored urine. Laboratory findings usually include elevated creatine phosphokinase, transaminases, BUN (blood urea nitrogen), creatinine, as well as hyperuricemia and hyperkalemia. Hypocalcemia and hypophosphatemia have also been reported. Compartment syndrome as a complication of rhabdomyolysis can arise due to muscle swelling, compressing nervous and vascular structures within the compartment [19].

Imaging of rhabdomyolysis by MRI is more sensitive than CT or ultrasound, allowing greater detail of the distribution and extent of affected muscles [19] (Fig. 4). Two types of MR imaging findings were described by $\mathrm{Lu}$ et al. [20]. Type 1 revealed homogeneously isointense to hyperintense T1weighted signal, homogenously high T2 and short tau inversion recovery sequences (STIR), and homogenous enhancement after IV contrast administration. Type 1 rhabdomyolysis is associated with overexertion from exercise [20]. While the
Fig. 3 Viral myositis (HIV) 48year-old. Axial STIR images through the mid-thighs reveals heterogeneous hyperintense signal affecting all compartments

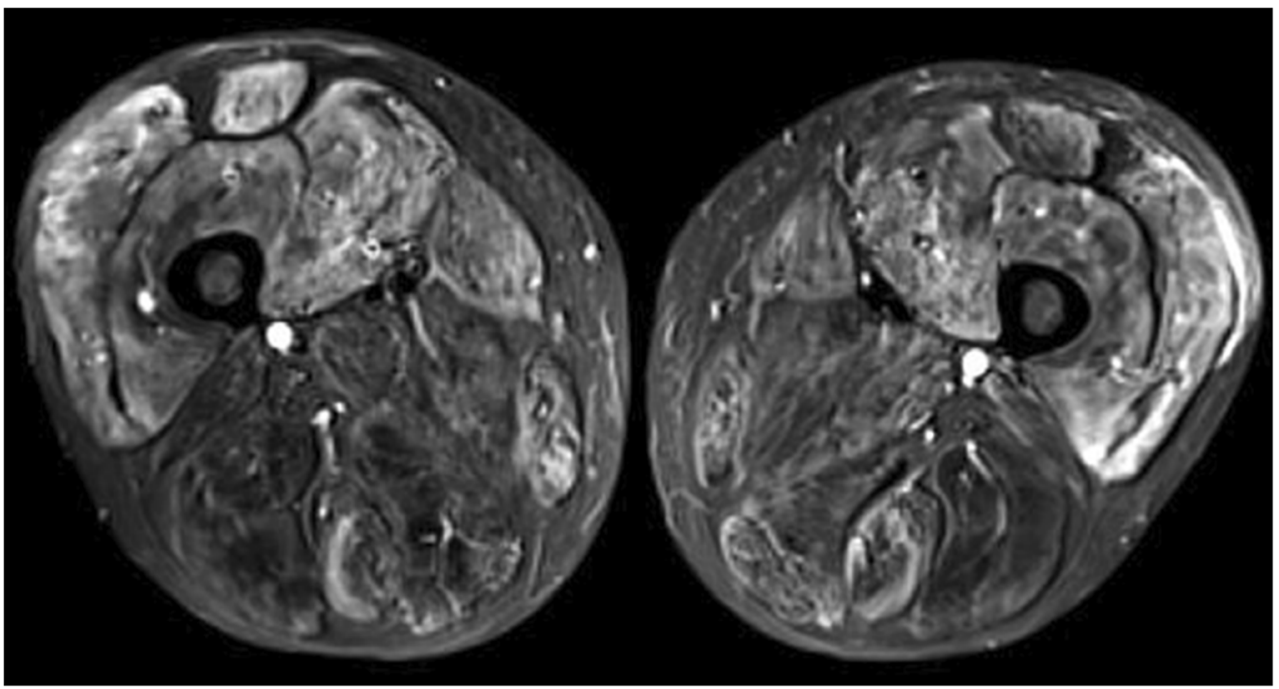


Fig. 4 ODCS with type 2, rhabdomyolysis in a 34-year-old. Coronal proton density fat saturation image (a) reveals patchy, heterogeneously hyperintense images of the right hip musculature after being "found down" due to OxyContin overdose. Note the bulging piriformis (star), gluteus minimus (diamond), and gluteus medius (arrowhead) muscles and fluid tracking along the proximal iliotibial band. Coronal T1 image (b) of the same patient

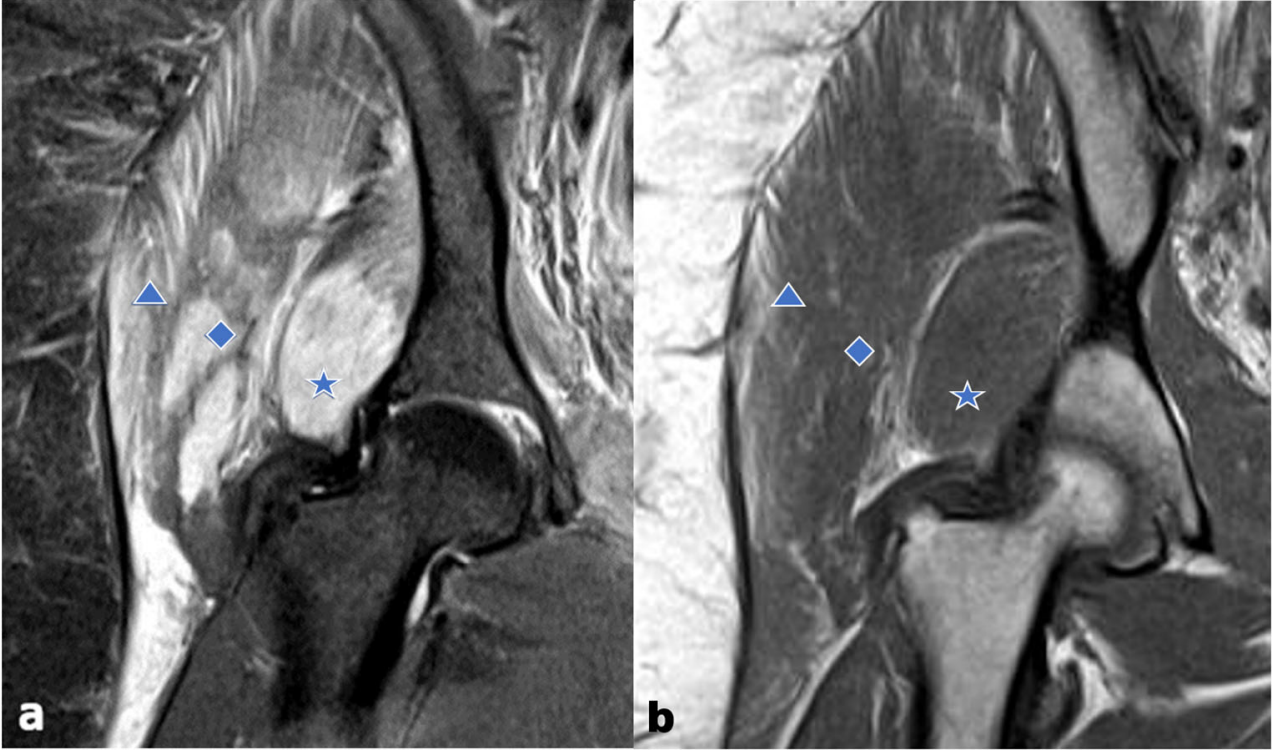

upper and lower extremities are often involved, axial compartments of the trunk, including the paraspinal, deltoid, abdominal, and gluteal muscle groups, have been reported [21-23].

In type 2 rhabdomyolysis, either homogeneous or heterogenous isointense to hyperintense signal on T1 imaging, heterogenous hyperintensity on T2 or STIR sequences, and rim-enhancement daubed the "stipple sign" is seen on post contrast T1-weighted sequences. The rimenhancing foci represent areas of myonecrosis [20]. The MR findings of type 2 rhabdomyolysis are found in patients with overdose compartment syndrome (ODCS), blunt trauma, vascular occlusion, and carbon monoxide poisoning [24]. Intramuscular hemorrhage can be seen as hyperintense T1-weighted signal abnormalities and signal void or blooming artifacts on gradient-echo sequences [24] (Fig. 4).

\section{Drug-induced and immune-mediated necrotizing myositis}

Drug-induced myositis may also be encountered in the emergent or urgent setting. Drugs of abuse, namely, alcohol, cocaine, opiate, phencyclidine, and some wild mushrooms, have been documented causes of myositis [15, 25]. Synthetic cannabinoid-induced myositis leading to rhabdomyolysis has been reported [26] (Fig. 5).

Even more commonly, prescribed drugs have been implicated in causing myositis and ultimately muscle necrosis such as gabapentin [27], empagliflozin [28], statins, fibrates, cyclosporine, tacrolimus, propofol, labetalol, telbivudine, antipsychotics, voriconazole, entecavir, zidovudine, colchicine, selective serotonin reuptake inhibitors, and lithium, among others [15]. Typically, the myalgias associated with these drugs are self-limiting, resolving when the drug is ceased.

Fig. 5 Rhabdomyolysis in a 23year-old patient who presented to the emergency department 1 week after smoking synthetic cannabinoids with a creatine kinase of 203,700. Axial proton density fatsaturated image reveals selective but symmetric bilateral hyperintensity of all compartments with relative sparing of the adductor longus muscles (star) and vastus intermedius muscles (arrowhead) groups

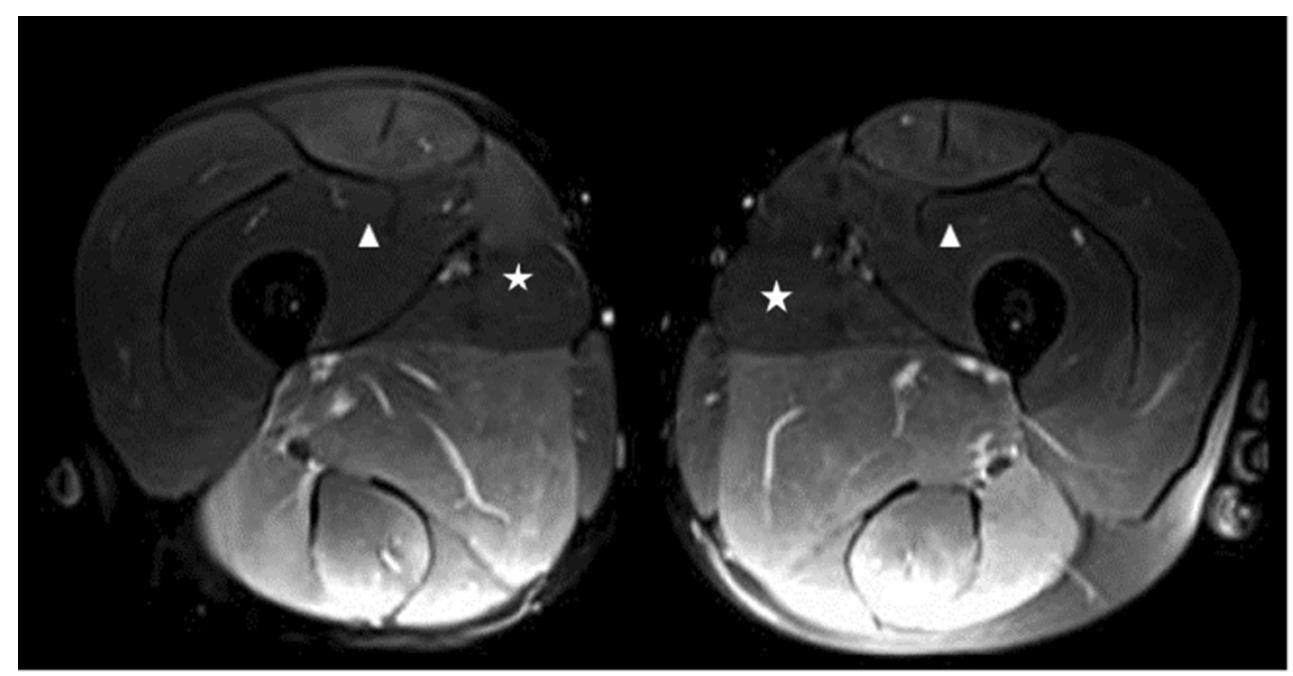


However, an increasingly recognized type of inflammatory myopathy is immune-mediated necrotizing myopathy (IMNM). IMNM is a novel subset of the family of inflammatory myopathies of which polymyositis, dermatomyositis, and inclusion body myositis are most well-known. In distinction to the other drug-induced causes of myositis, IMNM is difficult to treat because the drug, most commonly a statin, produces anti-3-hydroxy-3-methylglutaryl-coenzyme A reductase antibodies (anti-HMGCR) or anti-signal recognition particle (SRP) that continue to circulate long after the discontinuation of the offending agent [29]. Unlike, other inflammatory myopathies such as dermatomyositis, polymyositis, and inclusion body myositis which are the product of $\mathrm{T}$ cell-mediated attack of the muscle fibers, IMNM is an antibody-mediated response to the muscle fibers characterized by the presence of macrophages. These antibodies can be detected by immunoassays, obviating the need for muscle biopsy [30].

Patients can present to the emergency department with extreme fatigue, muscle soreness, and extremity weakness. Laboratory findings include markedly elevated CK and transaminase levels. The addition of myoglobinuria suggests progression to rhabdomyolysis. Of note, in contradistinction to non-inflammatory myopathies, IMNM patients CK levels fail to improve despite aggressive hydration. Long-term, aggressive, immunosuppressive therapies are the current treatment, and several months of therapy may be required before $\mathrm{CK}$ levels normalize [30]. MRI examination may reveal diffusely hyperintense $\mathrm{T} 2$-weighted signal within affected muscle groups, consistent with muscle edema of myositis [30]. Additional findings include muscle atrophy and fatty replacement which is more severe in patients with anti-SRP antibodies [29]. Elessawy et al. utilized whole-body MRI for a variety of chronic myositis. He used coronal STIR and T1 sequences with a total scan time ranging from 15 to $20 \mathrm{~min}$ [31]. Using a whole-body technique allowed for the detection of bilateral and early asymptomatic myositis muscles groups.

\section{Diabetic myonecrosis}

Diabetic myonecrosis (DMN), also called diabetic muscle infarcts, is a sequela seen in patients that have longstanding, suboptimal glycemic control [32]. Characterized by acute onset pain with or without a focal mass and reduced range of mobility, these patients may have a low-grade fever and a mildly elevated CK; however, leukocytosis is usually absent. Chronic diabetic renal disease seems to be the common factor, predicting incidence and recurrence of DMN [32]. Other stigmata of uncontrolled diabetes are often present such as neuropathy and retinopathy. Jelinek et al. studied 21 patients and found that the thigh was most commonly affected site (81\%), followed by the calf (19\%). Up to $38 \%$ of these patients had bilateral infarcts, $62 \%$ had multicompartmental involvement, and $86 \%$ had more than three muscles involved. Combined thigh and calf involvement were present in $10 \%$ of patients [33].

MRI is the study of choice for imaging DMN because it clearly identifies the location, number, and extent of disease involvement. Muscle swelling, exhibiting isointense T1weighted signal and hyperintense $\mathrm{T} 2$-weighted/inversion-recovery signal are the usual imaging characteristics (Fig. 6). Subfascial and subcutaneous edema may be present [33]. Diffuse enhancement on gadolinium-enhanced T1-weighted imaging typically corresponds to the hyperintense T2weighted signal abnormalities; however, $29 \%$ of the patients studied by Jelinek et al. exhibited small rim-enhancing foci with low central $\mathrm{T} 1$-weighted signal. These rim-enhancing components represent muscle infarction and necrosis. Fourteen percent of patients had small foci of both hyperintensity $\mathrm{T} 1$-weighted and $\mathrm{T} 2$-weighted signal abnormalities corresponding with post-infarct hemorrhage [33].

While highly sensitive, the specificity of MRI is limited by an extensive differential diagnosis, including soft tissue abscess, pyomyositis, necrotizing fasciitis, inflammatory myositis, and primary muscle lymphoma. Therefore, DMN remains a clinical and imaging diagnosis [33]. A clinical history of uncontrolled, insulin-dependent, complicated diabetes with sudden onset thigh and/or calf pain without overt signs of infection should raise the suspicion of DMN. These findings, in addition to bilateral or simultaneously discontinuous sites of disease on MRI imaging, can lead one to the diagnosis of DMN. In contradistinction to DMN, necrotizing fasciitis is more likely to have fever, cellulitis, and leukocytosis [33]. Occasionally, histopathologic diagnosis via a percutaneous biopsy is required for cases of diagnostic dilemma.

\section{Paraneoplastic myositis and polymyositis}

While a rare disease, with an incidence of approximately $1 / 100,000$, adult-onset dermatomyositis is associated with a concomitant malignancy in 15-30\% [34]. Paraneoplastic polymyositis may herald a yet undiagnosed malignancy or coincide with a tumor diagnosis. Occasionally, paraneoplastic dermatomyositis or polymyositis patients can present to the emergency department or urgent care center experiencing proximal muscle weakness, myalgias, and elevated muscle enzymes. Croce et al. report a case of severe paraneoplastic polymyositis in a 38-year-old patient who presented with myalgias and proximal muscle weakness and ultimately was diagnosed with a breast mass [35]. Min et al. reported a similar clinical scenario of 45-year-old patient presenting to an emergency department who exhibited significantly elevated muscle enzymes and myoglobin. Min et al.'s patient was discovered to have a serous ovarian carcinoma that caused a rapidly progressing paraneoplastic necrotizing myopathy [36]. Given the rarity of paraneoplastic polymyositis, MRI imaging of 


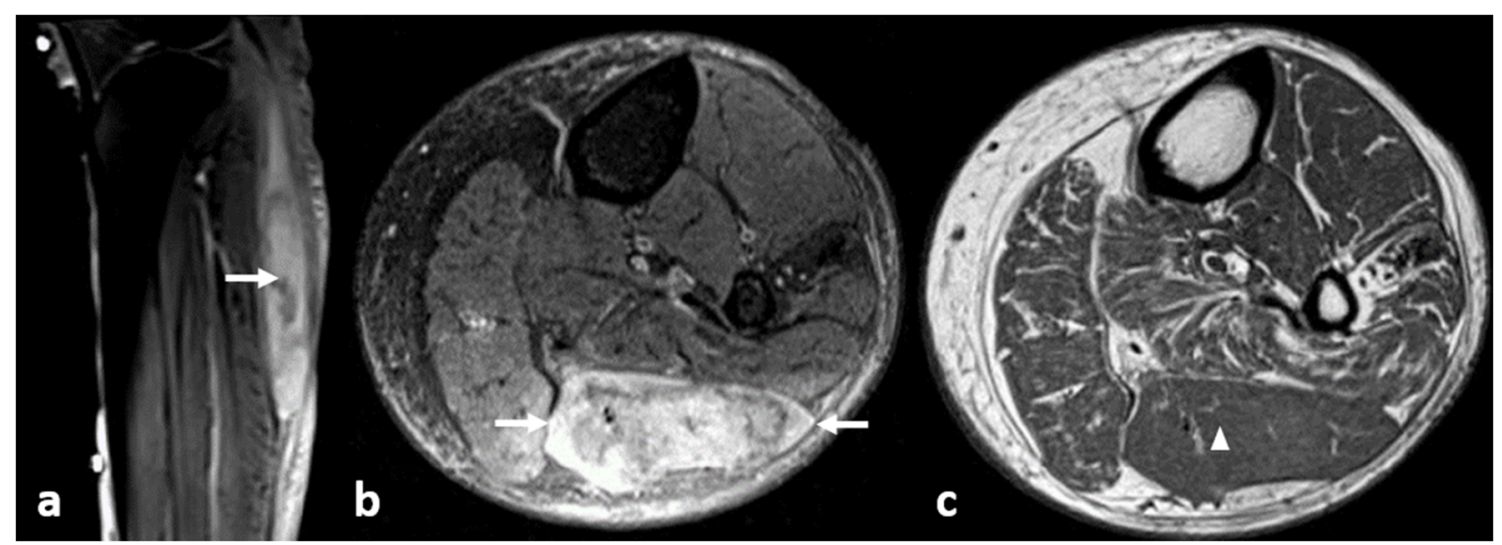

Fig. 6 Diabetic myonecrosis in a 48-year-old patient who presented to the emergency department with acute calf pain and a long history of uncontrolled diabetes, including nephropathy and retinopathy. Sagittal STIR image (a) reveals heterogeneous, hyperintense signal within the superficial posterior compartment (arrow). Axial PD fat saturation images through the calf (b) reveals heterogenous hyperintense T2-weighted signal throughout the lateral gastrocnemius muscle (arrows). Axial T1 image (c) notes isointense effacement of intermuscular fat within the lateral gastrocnemius relative to the surrounding musculature (arrowhead)

monitoring device can be used to quantitate the compartment pressures. A sustained intracompartment pressure (ICP) of (> $30 \mathrm{mmHg}$ ) or perfusion pressure (diastolic BP-ICP) of less than $30 \mathrm{mmHg}$ is considered abnormal [38]. The medicolegal risks associated with a "missed or delayed compartment releases have resulted in some of the highest indemnity payments in orthopedic litigation" [39].

While MR should not delay surgery in manifest ACS cases for more than $1 \mathrm{~h}$, if signs and symptoms are equivocal, MR can play an adjunctive diagnostic role [40]. Rominger et al. described a loss of normal muscle septation or architecture on $\mathrm{T} 1$ imaging and diffuse increased signal intensity on T2weighted images in cases of compartment syndrome. Contrast enhancement of these cases was variable, but intense muscle enhancement was noted early in the process. As tissue became devitalized, enhancement patterns became more variable. The development of fluid collections may have represented muscle necrosis. Late or follow-up imaging revealed areas of fibrosis and fatty infiltration [40] (Fig. 10).

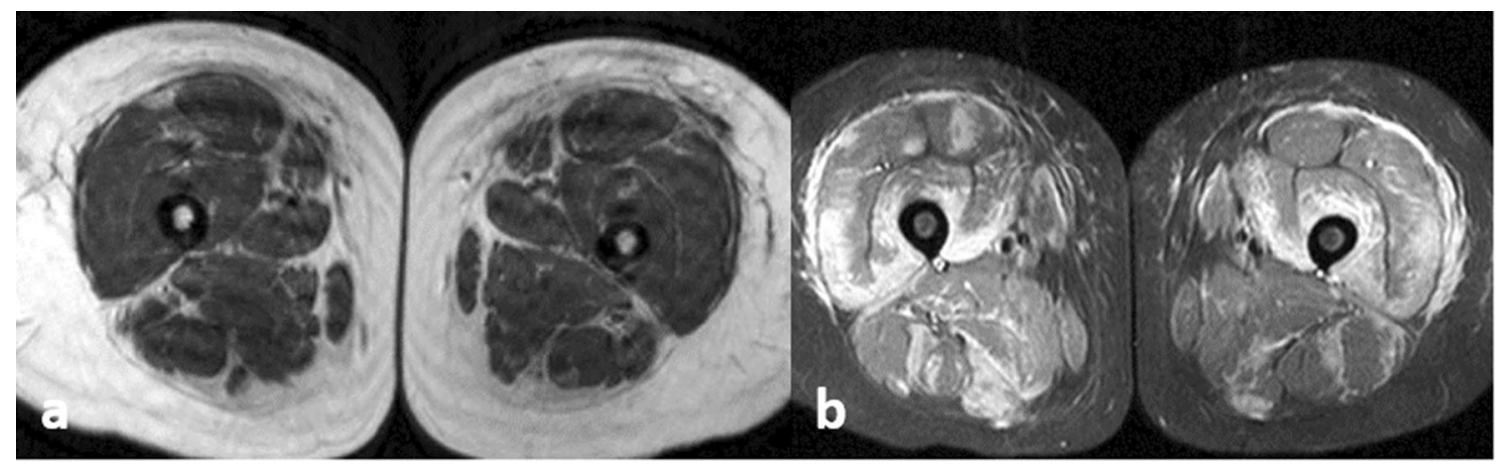

Fig. 7 Polymyositis. Axial T1-weighted image (a) through the mid-thigh reveals mildly increased but isointense bilateral muscle swelling. Axial proton density fat-saturated image (b) through the same level reveals patchy hyperintense signal within all compartments with relatively sparing of some posterior and medial compartment muscles 
Fig. 8 Dermatomyositis in 59year-old. Axial STIR image of the lower pelvis reveals patient with diffusely increased hyperintensity of the obturator internus (circle) and obturator externus muscles (arrowhead) due to chronic, steroid-resistant dermatomyositis. Patient succumbed to respiratory failure within 1 month of this image

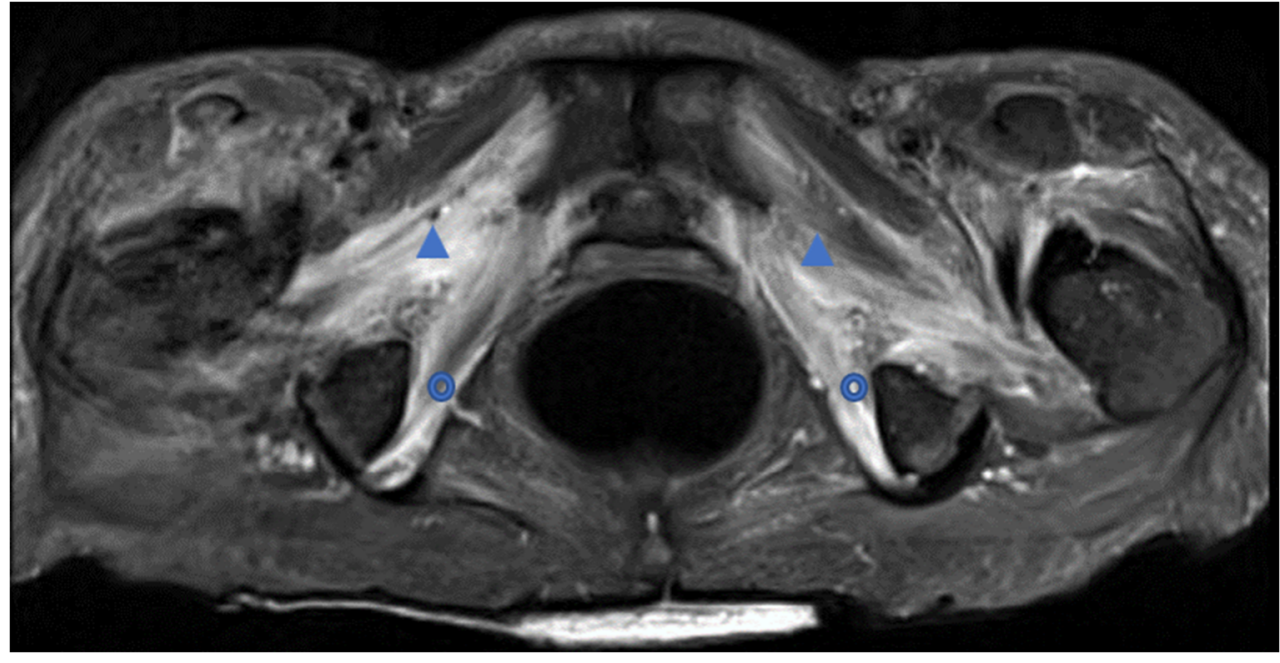

\section{Overdose compartment syndrome}

Nontraumatic or less acute causes of compartment syndrome can pose more of a diagnostic dilemma. This type of compartment syndrome often produces vague symptoms, and obtunded patients may require more of an investigative work-up to elucidate the cause and extent of the disease process. The physical signs and symptoms classically associated with compartment syndrome (six P's) may be either late findings or cannot be elicited due the patient's level of consciousness [38].

The combination of legally prescribed and illicit drug use has caused an opioid epidemic in North America. Eighty percent of the world's prescription opioids are consumed by Canadians and Americans, and there are 467,000 heroin addicts in the USA [41, 42]. A common scenario is the patient that is "found down" presenting with muscle compartment

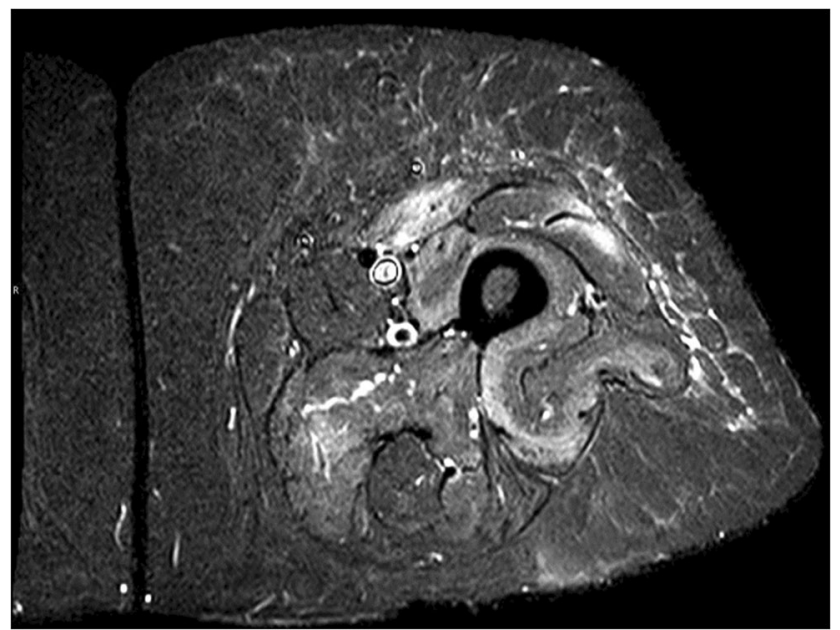

Fig. 9 A 59-year-old with rheumatoid arthritis and polymyositis. Axial STIR image of the left mid-thigh reveals patchy hyperintense involvement of all three compartments with some muscle sparing in the medial and posterior compartments. Note relative atrophy of the hyperintense muscles tension, varying degrees of functional deficit, and varying degrees of obtundation. Overdose compartment syndrome (ODCS) patients present differently than acute traumatic compartment syndrome, and there are no clear guidelines for treatment [42]. Parzych et al. prepared a retrospective analysis of 30 patients "found down" with clinical concern for compartment syndrome and found that these patients present with special diagnostic challenges. These patients are often unexaminable, have been immobile for an unspecified amount of time, and are often of "lower socioeconomic health status, leading to increased complication profile and less-reliable long-term follow-up" [42]. Compartment ischemia due to long-term immobility, lying on a hard-noncompliant surface, ultimately causes cell membrane destruction, tissue inflammation and damage (myositis), muscle necrosis, rhabdomyolysis, elevated compartment pressure, and compartment syndrome

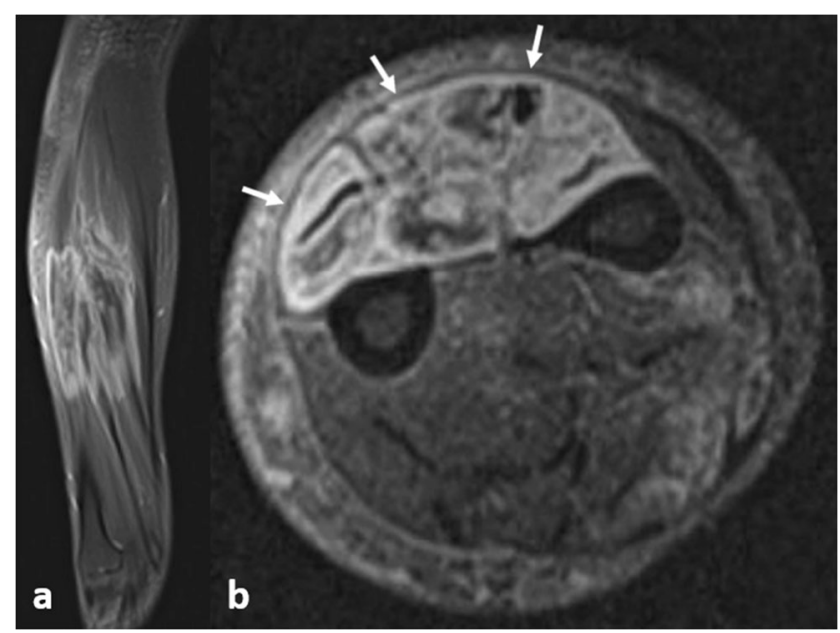

Fig. 10 Dorsal compartment syndrome of the forearm. Coronal proton density fat-saturation image (a) reveals heterogeneously hyperintense signal affecting the dorsal compartment due to blunt trauma. Axial short TI inversion recovery (STIR) (b) reveals bowing of the superficial deep fascia secondary to the swollen muscles throughout the dorsal compartment (arrows) 
[38]. Parzych et al.'s group reserved compartmental pressure measurements for patients who were unexaminable, believed to be down for a relatively short period of time, and who had compartments that were not frankly tense but had clinical concern for ongoing muscle necrosis [42]. Laboratory findings most often revealed an elevated creatinine, creatine phosphokinase, and lactate; however, there was no significant relationship between the laboratory findings and the degree of muscle necrosis found at surgery [42]. Compared to acute traumatic compartment syndrome, the gluteus muscles are more often affected with ODCS [43].

Given the difficulty assessing the signs and symptoms of ODCS, MRI may play a greater role in assessing these patients than in acute compartment syndrome. MRI may help to differentiate equivocal cases of compartment syndrome by revealing whether single or multiple muscle compartments are involved, by guiding selective compartment fasciotomies and avoiding unnecessary fasciotomies [40]. In addition, information on the overall extent of the process, detection of fascial bowing, muscle herniation, or focal fluid collections may prove useful.

MR findings of ODCS overlap with rhabdomyolysis and compartment syndrome exhibiting isointense to faintly hyperintense $\mathrm{T} 1$-weighted findings with muscle swelling, fascial bowing, and decreased definition of compartmental architectural detail. T2-weighted finding include diffuse or patchy hyperintensity. Post-contrast administration reveals variable levels of enhancement which may depend on the degree of tissue devitalization.

\section{Diagnosis of compartment syndrome}

Acute compartment syndrome (ACS) is the most severe complication of the entities we have described; however, many sources state that it is a "clinical diagnosis" [44, 45]. Despite this assertion, a study performed by Ulmer found the signs and symptoms use to diagnose acute compartment syndrome were debatable [46]. Specifically, Ulmer's research found a low sensitivity of $13 \%$ to $19 \%$; a positive predictive value of $11 \%$ to $15 \%$; specificity of $97 \%$; and a negative predictive value of $98 \%$. He concluded that the "clinical features of compartment syndrome of the lower leg are more useful by their absence in excluding the diagnosis then they are when present in confirming the diagnosis" [46].

The measurement of intracompartmental pressure is an attempt to objectify the diagnosis of ACS. Large et al. considered a compartment pressure difference of greater than $5 \mathrm{mmHg}$ from the standard to be a significant deviation in their study. They found that the most competent operators, using correct technique, achieved the acceptable standard only $60 \%$ of the time. Accuracy decreased to $42 \%$ if there were small errors in technique and $22 \%$ when catastrophic errors were committed [47]. Moreover, additional errors led to sampling unintended compartments and failure to penetrate the fascia with the needle [47].

The lack of sensitivity of the classic clinical signs and symptoms for ACS, combined with the questionable accuracy of intracompartmental pressure tests, raises concerns when deciding whether to perform a fasciotomy. Fitzgerald et al. performed a retrospective study of 60 patients and concluded that wounds sustained secondary to fasciotomy were "associated with marked morbidity and of such an appearance that their lifestyles were altered" [48]. Similarly, Lim et al. concluded that "as necessary as they are, fasciotomies are not benign procedures" and that "less invasive tests" may help to reduce unnecessary fasciotomies [49].

As discussed, MRI can play an adjunct role in in the diagnosis of myositis by identifying the location, distribution, and extension of the disease process. MRI is also useful in presurgical planning by accurately revealing vital information about the proximity of anatomic structures and by identifying fluid collections that may indicate abscesses or tissue necrosis. MRI is the imaging modality of choice in many cases of myositis, especially in cases that do not involve imminent intervention in order to prevent tissue devitalization. However, given the aforementioned limitations in diagnosis, invasive testing, and treatment morbidity, we posit that MRI may have a role yet to play in ACS. We have seen how rapid MRI scans play an important role in acute brain ischemia, using abbreviated protocols to quickly discriminate between strokes to be treated with IV-tPA and stroke mimics [50]. Similarly, the shorter length of time from injury to fasciotomy portends a better outcome for patients with ACS. A common mantra is that skeletal muscle ischemia for less than $3 \mathrm{~h}$ is reversible, and that ischemia for more than $4-8 \mathrm{~h}$ is irreversible. However, Vaillancourt et al. stated that these parameters did not comport with their intraoperative findings of tissue necrosis [51].

\section{Conclusion}

Myositis and other urgent muscle disorders can present in the emergent setting in several forms with varying levels of severity. Patients usually present with an array of complaints that range from myalgias and muscle swelling to decreased range of motion and weakness. Specific entities may include fever and leukocytosis, and many exhibit increased CK levels. Some patients are unresponsive due to their level of consciousness, precluding adequate assessment of history and physical exam. In addition, the classic physical signs and symptoms for the detection of ACS are low in sensitivity but high in specificity. Given the spectrum of findings, MRI remains a useful, sensitive, diagnostic tool that should be correlated with the available clinical and laboratory data. While some patients require urgent surgical intervention, most can 
be safely imaged using MR with relative haste considering the efficiency of modern protocols. Potential research incorporating 3D-isotropic volume sets with spectroscopy and elastography could be promising and help to refine the future specificity of MR imaging in this field.

\section{Compliance with ethical standards}

Conflict of interest The authors declare that have no conflict of interest.

\section{References}

1. Andrew N. Pollak M (2014) United States Bone and Joint Initiative: the Burden of Musculoskeletal Disease in the United States (BMUS). http://www.boneandjointburden.org. Accessed 2 Aug 2020

2. Johnstone AJ, Ball D (2019) Determining ischaemic thresholds through our understanding of cellular metabolism. BTI Compartment Syndrome: A Guide to Diagnosis and Management [Internet]. Chapter 4. Springer, Cham

3. Taylor DJ (2000) Clinical utility of muscle MR spectroscopy. Semin Musculoskelet Radiol 4(4):481-502. https://doi.org/10. 1055/s-2000-13172

4. Sedivy P, Drobny M, Dezortova M, Herynek V, Roztocil K, Cermakova H, Nemcova A, Dubsky M, Hajek M (2018) 31P-MR spectroscopy in patients with mild and serious lower limb ischemia. Int Angiol 37(4):293-299. https://doi.org/10.23736/s0392-9590. 18.03943-3

5. Kennedy PA-O, Barnhill E, Gray C, Brown C, van Beek EJR, Roberts N, Greig CA (2020) Magnetic resonance elastography (MRE) shows significant reduction of thigh muscle stiffness in healthy older adults. (2509-2723 (Electronic))GeroScience 42: 311-321. https://doi.org/10.1007/s11357-019-00147-2

6. Toomayan GA, Robertson F, Major NM, Brigman BE (2006) Upper extremity compartmental anatomy: clinical relevance to radiologists. Skelet Radiol 35(4):195-201. https://doi.org/10.1007/ s00256-005-0063-3

7. Boles CA, Kannam S, Cardwell AB (2000) The forearm. Am J Roentgenol 174(1):151-159. https://doi.org/10.2214/ajr.174.1. 1740151

8. Toomayan GA, Robertson F, Major NM (2005) Lower extremity compartmental anatomy: clinical relevance to radiologists. Skelet Radiol 34(6):307-313. https://doi.org/10.1007/s00256-005-0910-2

9. Burghardt RD, Siebenlist S, Dobele S, Lucke M, Stockle U (2010) Compartment syndrome of the thigh. A case report with delayed onset after stable pelvic ring fracture and chronic anticoagulation therapy. BMC Geriatr 10:51. https://doi.org/10.1186/1471-2318$10-51$

10. Lovejoy JF 3rd, Alexander K, Dinan D, Drehner D, Khan-Assad N, Lacerda IRA (2017) Team approach: pyomyositis. JBJS Rev 5(6): e4. https://doi.org/10.2106/jbjs.Rvw.16.00048

11. Yu JS, Habib P (2009) MR imaging of urgent inflammatory and infectious conditions affecting the soft tissues of the musculoskeletal system. Emerg Radiol 16(4):267-276. https://doi.org/10.1007/ s10140-008-0786-2

12. Ali SZ, Srinivasan S, Peh WC (2014) MRI in necrotizing fasciitis of the extremities. Br J Radiol 87(1033):20130560. https://doi.org/10. 1259/bjr.20130560

13. Chaudhry AA, Baker KS, Gould ES, Gupta R (2015) Necrotizing fasciitis and its mimics: what radiologists need to know. AJR Am J Roentgenol 204(1):128-139. https://doi.org/10.2214/ajr.14.12676
14. Nauss MD, Schmidt EL, Pancioli AM (2009) Viral myositis leading to rhabdomyolysis: a case report and literature review. Am J Emerg Med 27(3):372.e375-372.e376. https://doi.org/10.1016/j. ajem.2008.07.022

15. Day JA, Limaye V (2019) Immune-mediated necrotising myopathy: a critical review of current concepts. Semin Arthritis Rheum 49(3):420-429. https://doi.org/10.1016/j.semarthrit.2019.04.002

16. Richardson SJ, Lopez F, Rojas S, Cho S, Holodniy M, Herndier B, Katz J (2001) Multinodular polymyositis in a patient with human immunodeficiency and hepatitis C virus coinfection. (0148-639X (Print)) Muscle Nerve 24(3):433-437

17. Mosnier E, Charrel R, Vidal B, Ninove L, Schleinitz N, Harlé JR, Bernit E (2013) Toscana virus myositis and fasciitis. Med Mal Infect 43(5):208-210. https://doi.org/10.1016/j.medmal.2013.04. 002

18. Beydon M, Chevalier K, Al Tabaa O, Hamroun S, Delettre A-S, Thomas M, Herrou J, Riviere E, Mariette X (2020) Myositis as a manifestation of SARS-CoV-2. Ann Rheum Dis. https://doi.org/10. 1136/annrheumdis2020-217573

19. Moratalla MB, Braun P, Fornas GM (2008) Importance of MRI in the diagnosis and treatment of rhabdomyolysis. Eur J Radiol 65(2): 311-315. https://doi.org/10.1016/j.ejrad.2007.03.033

20. Lu CH, Tsang YM, Yu C-W, Yu Cw Fau - Wu M-Z, Wu Mz Fau Hsu C-Y, Hsu Cy Fau - Shih TT-F, Shih TT (2007) Rhabdomyolysis: magnetic resonance imaging and computed tomography findings. J Comput Assist Tomogr 31(3):368-374

21. Vanbrabant P, Moke L, Meersseman W, Vanderschueren G, Knockaert D (2015) Excruciating low back pain after strenuous exertion: beware of lumbar paraspinal compartment syndrome. J Emerg Med 49(5):641-643. https://doi.org/10.1016/j.jemermed. 2015.06.056

22. Farkash U, Shabshin N, Pritsch Perry M (2009) Rhabdomyolysis of the deltoid muscle in a bodybuilder using anabolic-androgenic steroids: a case report. J Athl Train 44(1):98-100. https://doi.org/10. 4085/1062-6050-44.1.98

23. Narayan N, Griffiths M, Patel HD (2013) Gluteal compartment syndrome with severe rhabdomyolysis. BMJ Case Rep 2013: bcr2013010370. https://doi.org/10.1136/bcr-2013-010370

24. Kok SXS, Tan TJ (2017) Clinics in diagnostic imaging (179). Severe rhabdomyolysis complicated by myonecrosis. Singapore Med J 58(8):467-472. https://doi.org/10.11622/smedj.2017081

25. Pearse R, Visagan R, Reddy K, Dev S (2019) Drug-induced paraspinal myositis mimicking acute bilateral sciatica. BMJ Case Rep 12(2). https://doi.org/10.1136/bcr-2018-224480

26. Sweeney B, Talebi S, Toro D, Gonzalez K, Menoscal JP, Shaw R, Hassen GW (2016) Hyperthermia and severe rhabdomyolysis from synthetic cannabinoids. Am J Emerg Med 34(1):121.e121121.e122. https://doi.org/10.1016/j.ajem.2015.05.052

27. Coupal TM, Chang DR, Pennycooke K, Ouellette HA, Munk PL (2017) Radiologic findings in gabapentin-induced myositis. J Radiol Case Rep 11(4):30-37. https://doi.org/10.3941/jrcr.v11i4. 3092

28. Gao F, Hall S, Bach LA (2020, 2020) Myopathy secondary to empagliflozin therapy in type 2 diabetes. Endocrinol Diabetes Metab Case Rep 2020. https://doi.org/10.1530/edm-20-0017

29. Pinal-Fernandez I, Casal-Dominguez M, Carrino JA-O, Lahouti AH, Basharat P, Albayda J, Paik JJ, Ahlawat S, Danoff SK, Lloyd TE, Mammen AL, Christopher-Stine L (2017) Thigh muscle MRI in immune-mediated necrotising myopathy: extensive oedema, early muscle damage and role of anti-SRP autoantibodies as a marker of severity. Ann Rheum Dis 76(4):681-687

30. Stroie OP, Boster J, Surry L (2020) Statin-induced immune-mediated necrotizing myopathy: an increasingly recognized inflammatory myopathy. Cureus 12(5):e7963. https://doi.org/10.7759/ cureus.7963 
31. Elessawy SS, Abdelsalam EM, Abdel Razek E, Tharwat S (2016) Whole-body MRI for full assessment and characterization of diffuse inflammatory myopathy. Acta Radiol Open 5(9): 2058460116668216. https://doi.org/10.1177/2058460116668216

32. Kempegowda P, Melson E, Langman G, Khattar F, Karamat M, Altaf QA (2019) Diabetic myonecrosis: an uncommon diabetic complication. (2052-0573 (Print)) Endocrinol Diabetes Metab Case Rep. https://doi.org/10.1530/EDM-19-0067

33. Jelinek JS, Murphey MD, Aboulafia AJ, Dussault RG, Kaplan PA, Snearly WN (1999) Muscle infarction in patients with diabetes mellitus: MR imaging findings. Radiology 211(1):241-247. https://doi.org/10.1148/radiology.211.1.r99ap44241

34. Kubeček O, Soukup T, Paulík A, Kopecký J (2016) Dermatomyositis with anti-TIF- $1 \gamma$ antibodies as a presenting symptom of underlying triple-negative breast cancer: a case report. BMC Cancer 16(1):684. https://doi.org/10.1186/s12885-0162715-1

35. Croce $\mathrm{S}$, Guèye M, Korganow AC, Chatelus E, Guèye SM, Diemunsch P, Mathelin C (2011) Paraneoplastic polymyositis associated with breast cancer: a therapeutic emergency. Breast Cancer Res Treat 126(3):811-814. https://doi.org/10.1007/ s10549-010-1328-7

36. Min KJ, Ouh YT, Hong HR, So KA, Hong JH, Lee JK (2014) Muscle weakness and myalgia as the initial presentation of serous ovarian carcinoma: a case report. J Ovarian Res 7:43. https://doi. org/10.1186/1757-2215-7-43

37. McQueen MM, Gaston P, Court-Brown CM (2000) Acute compartment syndrome. Who is at risk? J Bone Joint Surg Br 82 (2): 200-203. https://doi.org/10.1302/0301-620x.82b2 .9799

38. Jones AL, Rankin JA, Then KL (2020) Drug overdose, loss of consciousness, and compartment syndrome: a life-threatening combination. J Emerg Nurs 46(3):294-301. https://doi.org/10.1016/j. jen.2020.02.001

39. Little MTM, Lin CA, Vrahas MS (2019) Legal aspects of compartment syndrome. In: Mauffrey C, Hak DJ, Martin IM (eds) Compartment Syndrome: A Guide to Diagnosis and Management. Springer Copyright 2019, The Author(s), Cham, pp 9-16. https:// doi.org/10.1007/978-3-030-22331-1_2

40. Rominger MB, Lukosch CJ, Bachmann GF (2004) MR imaging of compartment syndrome of the lower leg: a case control study. Eur Radiol 14(8):1432-1439. https://doi.org/10.1007/s00330-0042305-5

41. Health Canada (2017) Canadian Centre on Substance Use and Addiction. Joint statement of action to address the opiod crisis: A collective response. https://www.ccsa.ca/sites/default/files/201904/CCSA- Joint-Statement-of-Action-Opioid-Crisis-AnnualReport-2017-en.pdf

42. Parzych L, Jo J, Diwan A, Swart E (2019) "Found down" compartment syndrome: experience from the front lines of the opioid epidemic. J Bone Joint Surg Am 101(17):1569-1574. https://doi.org/ $10.2106 /$ jbjs. 18.01307

43. Kuhlman GD, Gwathmey KG Gluteal compartment syndrome with neurologic impairment: report of 2 cases and review of the literature. (1097-4598 (Electronic))

44. Bourne RB, Rorabeck CH (1989) Compartment syndromes of the lower leg. Clin Orthop Relat Res (240):97-104

45. Mabee JR, Bostwick TL (1993) Pathophysiology and mechanisms of compartment syndrome. Orthop Rev 22(2):175-181

46. Ulmer T (2002) The clinical diagnosis of compartment syndrome of the lower leg: are clinical findings predictive of the disorder? J Orthop Trauma. 16(8):572--577. https://doi.org/10.1097/ 00005131-200209000-00006

47. Large TM, Agel J, Holtzman DJ, Benirschke SK, Krieg JC (2015) Interobserver variability in the measurement of lower leg compartment pressures. J Orthop Trauma 29(7):316-321. https://doi.org/ 10.1097/bot.0000000000000317

48. Fitzgerald AM, Gaston P, Wilson Y, Quaba A, McQueen MM (2000) Long-term sequelae of fasciotomy wounds. Br J Plast Surg 53(8):690-693. https://doi.org/10.1054/bjps.2000.3444

49. Lim KBL, Laine T, Chooi JY, Lye WK, Lee BJY, Narayanan UG (2018) Early morbidity associated with fasciotomies for acute compartment syndrome in children. J Child Orthop 12(5):480-487. https://doi.org/10.1302/1863-2548.12.180049

50. Paolini S, Burdine J, Verenes M, Webster J, Faber T, Graham CB, Sen S (2013) Rapid short MRI sequence useful in eliminating stroke mimics among acute stroke patients considered for intravenous thrombolysis. J Neurol Disord 1:137. https://doi.org/10.4172/ 2329-6895.1000137

51. Mortensen SJ, Zhang D, Mohamadi A, Collins J, Weaver MJ, Nazarian A, von Keudell AG (2020) Predicting factors of muscle necrosis in acute compartment syndrome of the lower extremity. Injury 51(2):522-526. https://doi.org/10.1016/j.injury.2019.11.022

Publisher's note Springer Nature remains neutral with regard to jurisdictional claims in published maps and institutional affiliations. 